\title{
К вопросу о влиянии огня на насаждения с участием Armeniaca mandshurica (Maxim.) Kostina в лесах Южного Приморья
}

\section{To the question of the influence of fire on plantings with the participation of Armenianca mandshurica (Maxim.) Kostina in the forests of Southern Primorye}

Епифанова Т. Ю.

Epifanova T. Yu.

\author{
Федеральный научный центр биоразнообразия наземной биоты Восточной Азии ДВО РАН, г. Владивосток, Россия. \\ E-mail: tepifanova@mail.ru \\ Federal Scientific Center for Biodiversity of terrestrial biota of East Asia, Far East Branch, Russian Academy of Sciences, \\ Vladivostok, Russia
}

\begin{abstract}
Peфepam. Снижение встречаемости, вплоть до исчезновения целых популяций позволяет считать абрикос маньчжурский - Armeniaca mandshurica (Maxim.) Kostina одной из редких плодовых пород Дальнего Востока. A. mandshurica относится к реликтовым растениям Приморского края Российской Федерации, причем, по нашему мнению, к очень сильно регрессирующим реликтам, так как ареал абрикоса заметно сократился за последние годы под влиянием активной деятельности человека. Лесная растительность самой освоенной жителями Приморского края части, в границах ареала А. mandshurica в значительной степени пострадала от ежегодных лесных пожаров. Систематические лесные пожары, уничтожая молодое поколение абрикоса, создают угрозу исчезновения этого вида в Южном Приморье Российской федерации. В работе приведены предварительные результаты изучения устойчивости A. mandshurica к огню, а также влияния огня на его естественное возобновление в лесах Дальнего Востока. Нами отмечена повышенная способность А. mandshurica противостоять огню. После пожаров поврежденные и обгоревшие экземпляры вновь способны давать поросль, главным образом от шейки корня.
\end{abstract}

Ключевые слова. Абрикос маньчжурский, лесная растительность, лесные пожары, реликтовые растения, Южное Приморье.

Summary. Manchurian Apricot - Armeniaca mandshurica (Maxim.) Kostina is one of the rare fruit trees of the Far East. A. mandshurica belongs to relict plants of the Primorsky Krai of the Russian Federation. Moreover, in our opinion it belongs to strongly regressing relics, because the occurrence of apricot is reduced, and large populations disappear under the anthropogenic pressure. The forest vegetation of the most developed part of the Primorsky Krai, within the range of $A$. mandshurica, has been largely affected by the annual forest fires. Frequent forest fires, destroying the young generation of apricot, threaten the extinction of this species in the Southern Primorye of the Russian Federation. This article presents preliminary results of studying the resistance of $A$. mandshurica to fire, as well as the effect of fire on its natural regeneration in the forests of the Far East. We noted the increased ability of $A$. mandshurica to resist fire. After fires, damaged and burnt specimens are again able to produce shoots, mainly from the root neck.

Key words. Armeniaca mandshurica, forest fires, forest vegetation, relict plants, Southern Primorye.

Вопросы о причинах возникновения лесных пожаров и последующем процессе восстановления растительности Приморского края, рассматривались многими лесоводами-исследователями (Колесников, 1955; Ярошенко, 1955; Васильев, 1958; Розенберг, Колесников, 1958; Попов, 1962; Куренцова, 1963; Комарова, 1986, 1992; Розенберг, 1999; и др.). Сведений же о влиянии пожаров на лесные насаждения с участием $A$. mandshurica в лесоводственных и геоботанических работах очень немного. Древесно-кустарниковая растительность Ханкайско-Раздольненской равнины практически ежегодно подвергается влиянию лесных пожаров. Возникновение и распространение этих явлений связано с особенностью климата данной территории, спецификой растительности и близостью к сельскохозяйственным угодьям (сенокосам), с которых ранней весной и поздней осенью огонь переходит на 
естественную лесную растительность (Ярошенко, 1955; Розенберг, Колесников, 1958; Куренцова, 1962; Епифанова, 1999; Манько, Епифанова, 2008 и др.). Весной и осенью при наступлении сухой, ветреной и теплой погоды пожарная опасность в лесах южного Приморья возрастает в разы. По данным Н. А. Попова (1962), «возникновению пожаров в это время года способствует скопление на поверхности почвы быстро высыхающего легко воспламеняющегося материала (мощный слой рыхлого опада). При значительной силе низовых пожаров почти полностью выгорают живой и мертвый напочвенный покров, подлесок, подрост и тонкомерная часть древостоя. Обгорает кора в нижней части деревьев и повреждаются обнаженные корни. Скорость распространения огня по ветру достигает $3-5$ км/час».

На сухих и периодически сухих местообитаниях A. mandshurica нередко становится спутником дуба монгольского - Quercus mongolica Fisch. ex Ledeb., высочайшая устойчивость которого к огню не вызывает сомнений и подтверждается многими исследователями (Усенко, 1984; Комарова, 1986; Цыбуков, Панченко, 1992; Епифанова, 1999; Добрынин, 2000). Эти данные свидетельствуют об устойчивости и A. mandshurica к воздействию огня, на что одними из первых обратили внимание В. А. Розенберг и Б. П. Колесников (1958). Впоследствии это подтвердили В. Н. Цыбуков и Л. М. Панченко (1992), по мнению которых A. mandshurica наиболее устойчив к огню по сравнению с другими лиственными породами Дальнего Востока; он даже более устойчив, чем Q. mongolica, который традиционно занимает первое место среди дальневосточных лиственных пород.

Прогоревшие в период с 2006 по 2016 гг. насаждения с A. mandshurica и послужили основными объектами наблюдений автора для изучения устойчивости этого вида к огню, а также влияния пожаров на насаждения с имеющимся естественным возобновлением абрикоса.

Для характеристики степени повреждения огнем и выживаемости деревьев на двух исследуемых участках общей площадью 0,5 га, производили сплошной перечет особей по ступеням толщины с установлением степени обгорания ствола. Для этого были приняты такие категории: без следов огня; обгорело до 0,25 окружности ствола; от 0,25 до 0,50 ; более 0,50 ; ствол обгорел полностью. Исследование естественного возобновления $A$. mandshurica после воздействия огня в естественных насаждениях осуществлялось нами на наиболее типичных участках леса. Вполне достаточной для объективной характеристики естественного лесовозобновления большинством исследователей признается минимальная площадь учета 100 м ${ }^{2}$ (Нестеров, 1948; Манько, 1959; Гуков, 1976). На площадках фиксировались количество, качество и возраст подроста, к которому относили все экземпляры A. mandshurica с диаметром до 4 см. Возрастная структура подроста и особенности его роста изучались на модельных экземплярах, отбираемых по высоте. При перечете подрост подразделялся на мелкий (0-50 см), средний (51-150 см), крупный (более 150 см в высоту и до 4 см в диаметре на высоте груди). По качественному состоянию подрост делился на здоровый (благонадежный), больной и усохший (к больным растениям относили те экземпляры, которые имеют различные механические повреждения, обгоревшие или искривленные стволики). Отдельно учитывали всходы (растения первого года жизни).

Некоторое представление о выживаемости A. mandshurica после влияния пожара получено на примере участка № 4-2007 (0,25 га), заложенного осенью 2007 г. в окрестностях села Кугуки Уссурийского района. Во время регулярных наблюдений отмечено, что на участке много сухой травы, представляющей в весеннее и осеннее время легко воспламеняющийся материал. Древостой был пройден низовым пожаром весной 2007 г., при котором сильно пострадал подлесок из леспедецы двуцветной Lespedeza bicolor Turcz., а стволы деревьев сильно обгорели (табл. 1). На участке в результате пожара погибло 56 \% деревьев (163 шт.), причем наиболее пострадал подрост (ступень толщины 2 см), на сухие особи которого приходится $48 \%$ от общего числа погибших растений. Количество погибших особей в подросте по породам распределилось так: A. mandshurica-2; Q. mongolica - 50; береза даурская Betula davurica Pall. - 15; ильм японский - Ulmus japonica (Rehder) Sarg. - 12. В ступени толщины 4 см существенно пострадало только два деревца A. mandshurica. У растений большого диаметра повреждения коры были не очень заметны и носили легкий поверхностный характер, в связи с чем деревья сохраняли свою жизнеспособность. Распределение всех усохших после пожара деревьев по породам выглядит так: A. mandshurica - 4\%, Q. mongolica $-57 \%$, U. japonica - $90 \%$, B. davurica - $91 \%$. Таким образом, жизнеспособность $A$. mandshurica оказалась наиболее высокой по сравнению с другими древесными породами. 
«Проблемы ботаники Южной Сибири и Монголии» - XVIII Международная научно-практическая конференция

Таблица 1

Распределение деревьев по толщине и состоянию после пожара в леспедецевом дубняке (ПП 4-2007)

\begin{tabular}{|c|c|c|c|c|c|c|}
\hline \multirow{2}{*}{$\begin{array}{c}\text { Ступени } \\
\text { толщины, } \\
\text { см }\end{array}$} & \multirow[b]{2}{*}{ Категории деревьев } & \multicolumn{5}{|c|}{ Количество деревьев (шт.) по породам } \\
\hline & & $\begin{array}{c}\text { Quercus. } \\
\text { mongolica }\end{array}$ & $\begin{array}{c}\text { Armeniaca } \\
\text { mandshurica }\end{array}$ & $\begin{array}{c}\text { Betula. } \\
\text { davurica }\end{array}$ & $\begin{array}{c}\text { Ulmus } \\
\text { japonica }\end{array}$ & Итого \\
\hline \multirow{3}{*}{2} & жизнеспособные & 5 & 5 & - & 2 & 12 \\
\hline & сомнительные & 10 & 2 & 1 & - & 13 \\
\hline & усохшие & 50 & 2 & 15 & 12 & 79 \\
\hline \multirow{3}{*}{4} & жизнеспособные & - & 0 & 1 & - & 1 \\
\hline & сомнительные & - & 2 & 1 & - & 3 \\
\hline & усохшие & 22 & 0 & 20 & 5 & 47 \\
\hline \multirow{3}{*}{6} & жизнеспособные & 10 & - & - & - & 10 \\
\hline & сомнительные & 2 & - & - & - & 2 \\
\hline & усохшие & 5 & - & 2 & - & 7 \\
\hline \multirow{3}{*}{8} & жизнеспособные & 10 & 2 & 1 & - & 13 \\
\hline & сомнительные & 5 & - & - & - & 5 \\
\hline & усохшие & 10 & - & - & - & 10 \\
\hline \multirow{3}{*}{10} & жизнеспособные & - & 5 & - & - & 5 \\
\hline & сомнительные & 2 & 2 & - & - & 4 \\
\hline & усохшие & 6 & - & 4 & 1 & 11 \\
\hline \multirow{3}{*}{12} & жизнеспособные & 5 & 5 & - & 0 & 10 \\
\hline & сомнительные & - & - & - & - & - \\
\hline & усохшие & 4 & - & - & - & - \\
\hline \multirow{3}{*}{14} & жизнеспособные & 3 & 2 & - & - & 5 \\
\hline & сомнительные & 10 & 8 & - & - & 18 \\
\hline & усохшие & 5 & - & - & - & 5 \\
\hline \multirow{3}{*}{16} & жизнеспособные & 14 & 12 & - & - & 26 \\
\hline & сомнительные & - & 1 & - & - & 1 \\
\hline & усохшие & $\begin{array}{ll}- \\
-\end{array}$ & - & $\begin{array}{ll}- \\
-\end{array}$ & $\begin{array}{ll}- \\
-\end{array}$ & - \\
\hline \multirow{3}{*}{ всего } & $\begin{array}{c}\text { Жизнеспособные, } \\
\text { шт \% }\end{array}$ & $47 / 26$ & $31 / 65$ & $2 / 4$ & $2 / 10$ & $82 / 28$ \\
\hline & $\begin{array}{c}\text { Сомнительные, } \\
\text { шт \% }\end{array}$ & $29 / 17$ & $15 / 31$ & $2 / 4$ & - & $46 / 16$ \\
\hline & Усохшие, шт $\mid \%$ & $102 / 57$ & $2 / 4$ & $41 / 91$ & $18 / 90$ & $163 / 56$ \\
\hline \multicolumn{2}{|r|}{ Итого: штү\% } & $178 / 61$ & $48 / 16$ & $45 / 15$ & $20 / 8$ & $291 / 100$ \\
\hline
\end{tabular}

Данные по повреждаемости огнем A. mandshurica были получены и на другой пробной площади 3-2009, заложенной в июле 2009 г. в верхней части пологого $\left(15^{\circ}\right)$ юго-западного склона сопки “Острая" на высоте 250 м над ур. м., в окр. с. Борисовка Уссурийского района.

Участок неоднократно повреждался беглыми низовыми пожарами; наиболее сильно пострадал древостой от огня осенью 2008 г. На стволах деревьев остались нагары высотой до 1,5-2,5 м. Подлесок из леспедецы был полностью уничтожен. В результате пожара обгоревшими в той или иной мере оказалось $30 \%$ стволов A. mandshurica, $52 \%$ стволов Q. mongolica, $70 \%$ липы амурской - Tilia amurensis Rupr., 74 \% березы ребристой - Betula costata Trautv. Ни одного погибшего дерева A. mandshurica на участке не встречено, тогда как усыхающие деревья $Q$. mongolica, относящиеся к ступеням толщины 4-8 см, присутствовали в количестве 5 \% (табл. 2).

По результатам исследований можно сделать вывод, что пожары оказывают огромное влияние на естественное возобновление A. mandshurica. Подрост этой породы до 2 см толщиной независимо от происхождения, к сожалению, полностью уничтожается во время прохождения огня. Как правило, возраст подроста абрикоса и других древесных пород редко превышает давность последнего прогорания. Тонкий слой коры молодых растений не способен защитить камбий от повреждения огнем. С пятилет- 


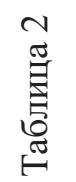

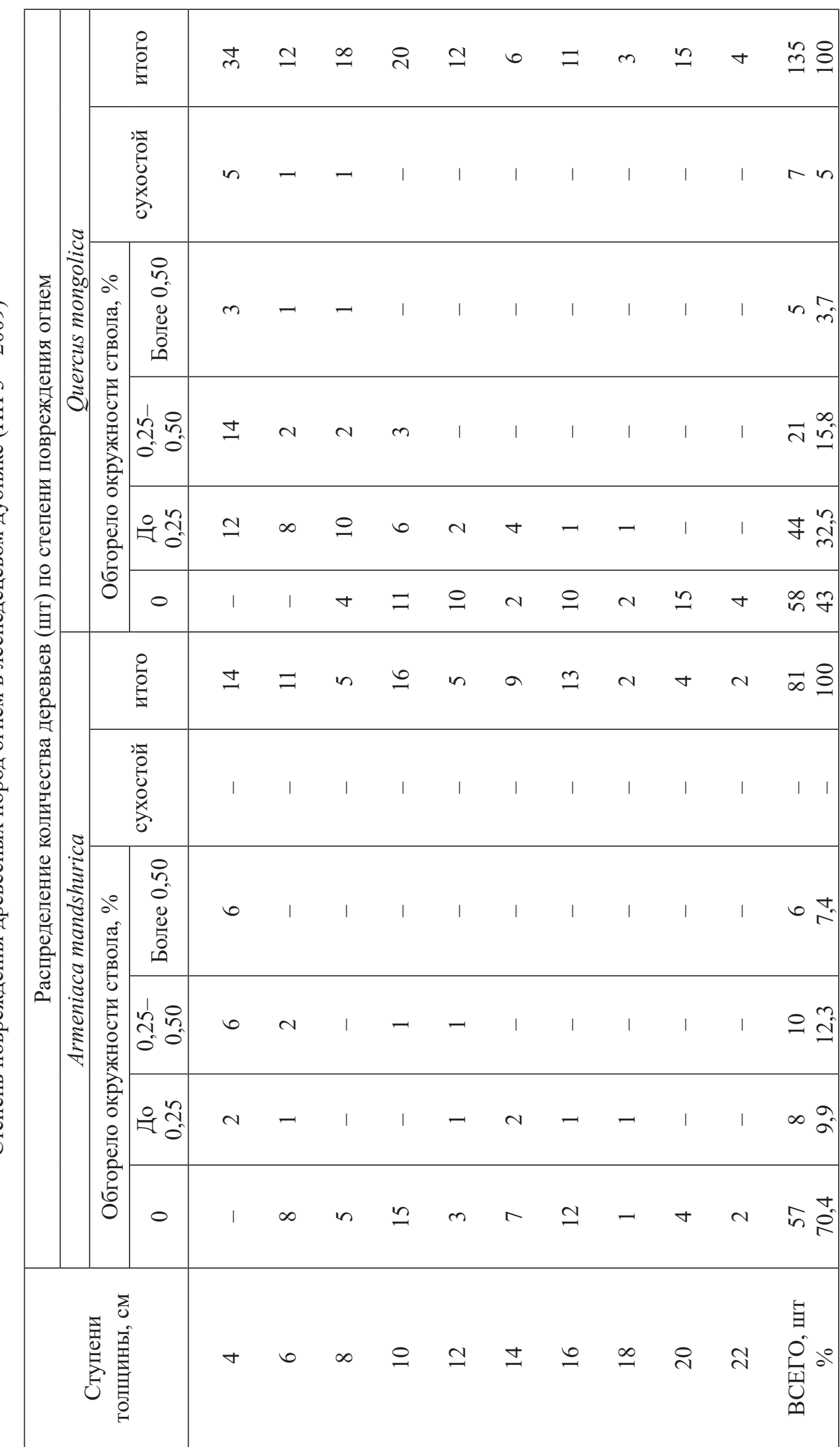


«Проблемы ботаники Южной Сибири и Монголии» - XVIII Международная научно-практическая конференция

\begin{tabular}{|c|c|c|c|c|c|c|c|c|c|c|c|c|c|}
\hline \multirow{12}{*}{ 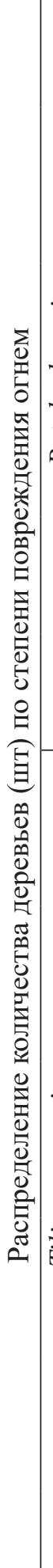 } & & $\begin{array}{l}\stackrel{\circ}{\circ} \\
\stackrel{\circ}{G}\end{array}$ & 1 & - & $n$ & $\sim$ & $\infty$ & $m$ & - & $\sim$ & I & 1 & ¿ะ \\
\hline & & 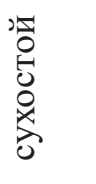 & 1 & - & - & 1 & 1 & 1 & 1 & 1 & 1 & 1 & a \\
\hline & \multirow{4}{*}{ 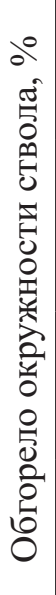 } & $\begin{array}{ll} & 0 \\
0 & 0 \\
0 & 0 \\
0 & 0 \\
10 & 0 \\
\end{array}$ & 1 & 1 & 1 & 1 & 1 & I & 1 & 1 & 1 & 1 & 11 \\
\hline & & $\begin{array}{ll}1 & \\
1 & 0 \\
n & n \\
n & 0 \\
0 & 0\end{array}$ & 1 & 1 & - & 1 & 1 & - & 1 & 1 & ' & 1 & Nå \\
\hline & & 욤 & 1 & 1 & $N$ & - & 0 & - & 1 & $\sim$ & 1 & 1 & 工 : \\
\hline & & 0 & 1 & 1 & - & - & $N$ & - & - & 1 & 1 & 1 & o \\
\hline & & $\begin{array}{l}\stackrel{̊}{0} \\
\stackrel{5}{\Xi}\end{array}$ & 0 & $m$ & - & 0 & - & I & 1 & - & $\sim$ & 1 & 요 \\
\hline & & 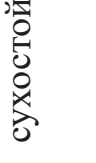 & - & - & - & - & 1 & 1 & 1 & 1 & 1 & 1 & $\nabla$ ণ \\
\hline & \multirow{4}{*}{ 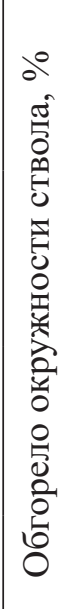 } & $\begin{array}{ll}0 & 0 \\
0 & 0 \\
0 & 0 \\
1 & 0\end{array}$ & - & - & 1 & 1 & 1 & I & 1 & 1 & 1 & 1 & 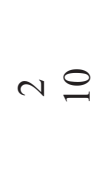 \\
\hline & & $\begin{array}{ll}1 & 0 \\
n & 0 \\
n & 0 \\
0 & 0\end{array}$ & $\nabla$ & 1 & 1 & - & 1 & I & 1 & 1 & 1 & 1 & $n \approx$ \\
\hline & & $\begin{array}{l}n \\
n \\
0 \\
0 \\
0 \\
\pi\end{array}$ & 1 & - & 1 & $\sim$ & 1 & 1 & 1 & 1 & 1 & 1 & $m \underline{n}$ \\
\hline & & 0 & 1 & 1 & 1 & $N$ & - & 1 & 1 & - & $N$ & 1 & 08 \\
\hline \multicolumn{3}{|c|}{ 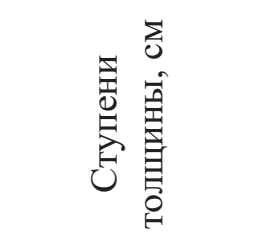 } & $\nabla$ & 6 & $\infty$ & 으 & $I$ & \pm & $\stackrel{0}{-}$ & $\infty$ & ิㅗ & ป & 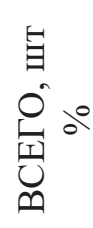 \\
\hline
\end{tabular}


него возраста, что соответствует у A. mandshurica ступеням толщины 4-6 см для порослевых экземпляров и 2-4 см для семенных, у растений можно отметить опробковение верхнего слоя коры. Оно выполняет функцию защиты от огня, воздействия низких температур и других неблагоприятных факторов.

Нами отмечена необычайная способность A. mandshurica противостоять огню. После пожаров поврежденные и обгоревшие экземпляры вновь дают поросль, главным образом от шейки корня. Способность пней $A$. mandshurica к побегообразованию не теряется даже после многократного повреждения огнем, а чем больше диаметр A. mandshurica, тем меньше погибших особей. Усыхающие и погибшие от огня экземпляры A. mandshurica толще 5 см на участках, пройденных беглыми низовыми пожарами, и вовсе отсутствовали. Также отмечено, что взрослые особи $A$. mandshurica наиболее устойчивы к воздействию огня. Поэтому, несмотря на практически ежегодно повторяющиеся пожары, деревья продолжают развиваться, цвести и даже плодоносить.

Однако слишком часто повторяющиеся или регулярные повреждения деревьев в виде ожогов стволов и корней способствуют их ослаблению, что сопровождается снижением урожая плодов и ухудшением процессов лесовозобновления. Корневая система A. mandshurica при ежегодных пожарах заметно ослабляется. В результате частых прогораний древостоев с участием A. mandshurica полнота и бонитет древостоя постепенно неизменно снижаются, происходят отрицательные изменения в составе подлеска и напочвенного покрова.

Многократные пожары ведут к деградации лесных насаждений и образованию порослевых древесно-кустарниковых зарослей с отсутствием или ограниченным участием A. mandshurica.

\section{ЛИТЕРАТУРА}

Bacuльев B. H. Происхождение флоры и растительности Дальнего Востока и Восточной Сибири // Материалы по истории флоры и растительности СССР. - М.; Л.: Изд-во АНСССР, 1958. - Вып. 3. - С. 361-457.

Гуков Г. В. Рекомендации по ведению хозяйства в лиственничных лесах Сихотэ-Алиня. - Владивосток, 1976. $-300 \mathrm{c}$.

Добрынин А. П. Дубовые леса российского Дальнего Востока (биология, география, происхождение). - Владивосток: Дальнаука, 2000. -260 с.

Enифанова T. Ю. Абрикос маньчжурский в прошлом и настоящем // Использование, восстановление и повышение продуктивности лесов Дальнего Востока: Юбилейный сборник научных трудов ИЛХ ПГСХА. - Уссурийск, 1998. - С. 182-187.

Enифанова T. Ю. Популяции абрикоса маньчжурского в приморском крае // Леса и лесообразовательный процесс на Дальнем Востоке: Материалы междунар. конф. - Владивосток: БПИ ДВО РАН, 1999. - С. 183-184.

Колесников Б. П. Очерк растительности Дальнего Востока. - Хабаровск: Хаб. кн. изд-во, 1955. - 104 с.

Комарова T. A. Семенное возобновление растений на свежих гарях (леса Южного Сихотэ-Алиня). - Владивосток: ДВНЦ АН СССР, 1986. - 224 с.

Комарова T. А. Послепожарные сукцессии в лесах Южного Сихотэ-Алиня. - Владивосток, 1992. - 224 с.

Куренцова Г. Э. Растительность приханкайской равнины и окружающих ее предгорий. - М.; Л.: Изд. АН CCCP, 1962. - $139 \mathrm{c}$.

Куренцова Г. Э. Ксерофитная растительность Приморья // Охрана природы на Дальнем Востоке. - Владивосток, 1963. - Вып. 1. - С. 69-75.

Манько Ю. И. К методике учета естественного лесовозобновления // Сообщ. ДВФ СО АН СССР, 1959. - Вып. II. - C. $27-32$.

Манько Ю. И., Епифанова Т. Ю. Абрикос маньчжурский // Красная книга Приморского края: Растения, 2008. - C. 196-197.

Нестеров В. Г. Методика изучения естественного возобновления леса. - Красноярск: Сиб. лесотехн. ин-т, 1948. $-26 \mathrm{c}$.

Попов Н. A. К вопросу о степени пожарной опасности и повреждаемость пожарами отдельных типов дубовых лесов южного Приморья // Лесн. журн., 1962. - № 5. - С. 27-29.

Розенберг В. А. Колесников Б. П. Порослевые древесно-кустарниковые заросли малолесных районов Приморского края // Вопросы реконструкции и повышения продуктивности лесов Дальнего Востока. Сер. ботан. Владивосток, 1958. - Т.4-6. - С. 5-46. 
Розенберг В. А. Антропогенная деградация биологического разнообразия и продуктивности смешанных лесов // Леса и лесообразовательный процесс на Дальнем Востоке: Материалы междунар. конф. - Владивосток: БПИ ДВО РАН, 1999. - С. 153-155.

Усенко Н. В. Деревья, кустарники и лианы Дальнего Востока. 2-е изд. перераб. и доп. - Хабаровск: Хаб. кн. изд-во, 1984. - 272 с.

Цыбуков В. Н., Панченко Л. М. Влияние пожаров на маньчжурский абрикос // Использование и восстановление лесов Дальнего Востока: Сб. научных трудов. - Уссурийск: ПСХИ, 1992. - С. 29-35.

Ярошенко П. Д. На Приханкайской равнине // Сов. Приморье, 1955. - № 18. - С. 247-256. 